\title{
The Ensuing Flood: Increasing Equity and Reducing Impact through Networked Decentralized Infrastructure
}

\author{
COURTNeY CROSSON, Architect, Assistant Professor
}

University of Arizona

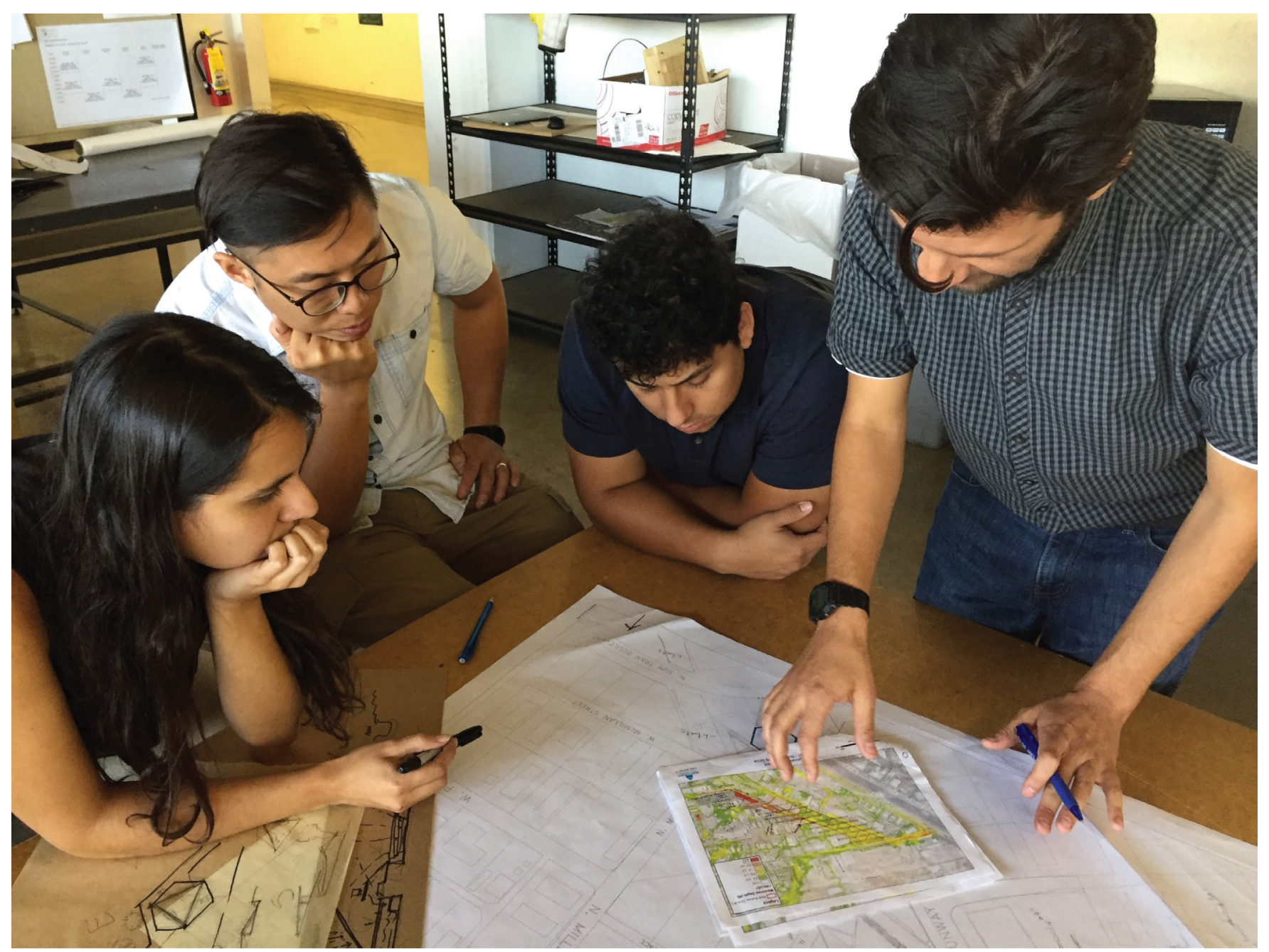

Figure 1. Students discuss the unique flooding features of their sites with Jacob Prietto, Principal Hydrologist for Pima County Regional Flood Control District, the sponsor of the studio. (Credit: Author)

INTRODUCTION: DESIGNING DECENTRALIZED, BOTTOM-UP, AND MULTI-BENEFIT INFRASTRUCTURE

The fourth National Climate Assessment warns of increases in the intensity and duration of precipitation events in the coming decades, leading to a greater severity and frequency of flash floods in portions of the United States. This concern is exacerbated by a national trend in deteriorating stormwater infrastructure and increased urbanization with densification of impervious land cover. In coastal cities with accelerated development, surge events overwhelm infrastructure that was not expanded with changes in land cover. In older cities with combined sewer systems, floods result in outflows of raw sewage into ecological zones. In sprawling cities with extreme seasonal storms, a historic failure to invest in infrastructure during periods of growth causes significant, annual property damage. The damages will worsen with the projected increases in 


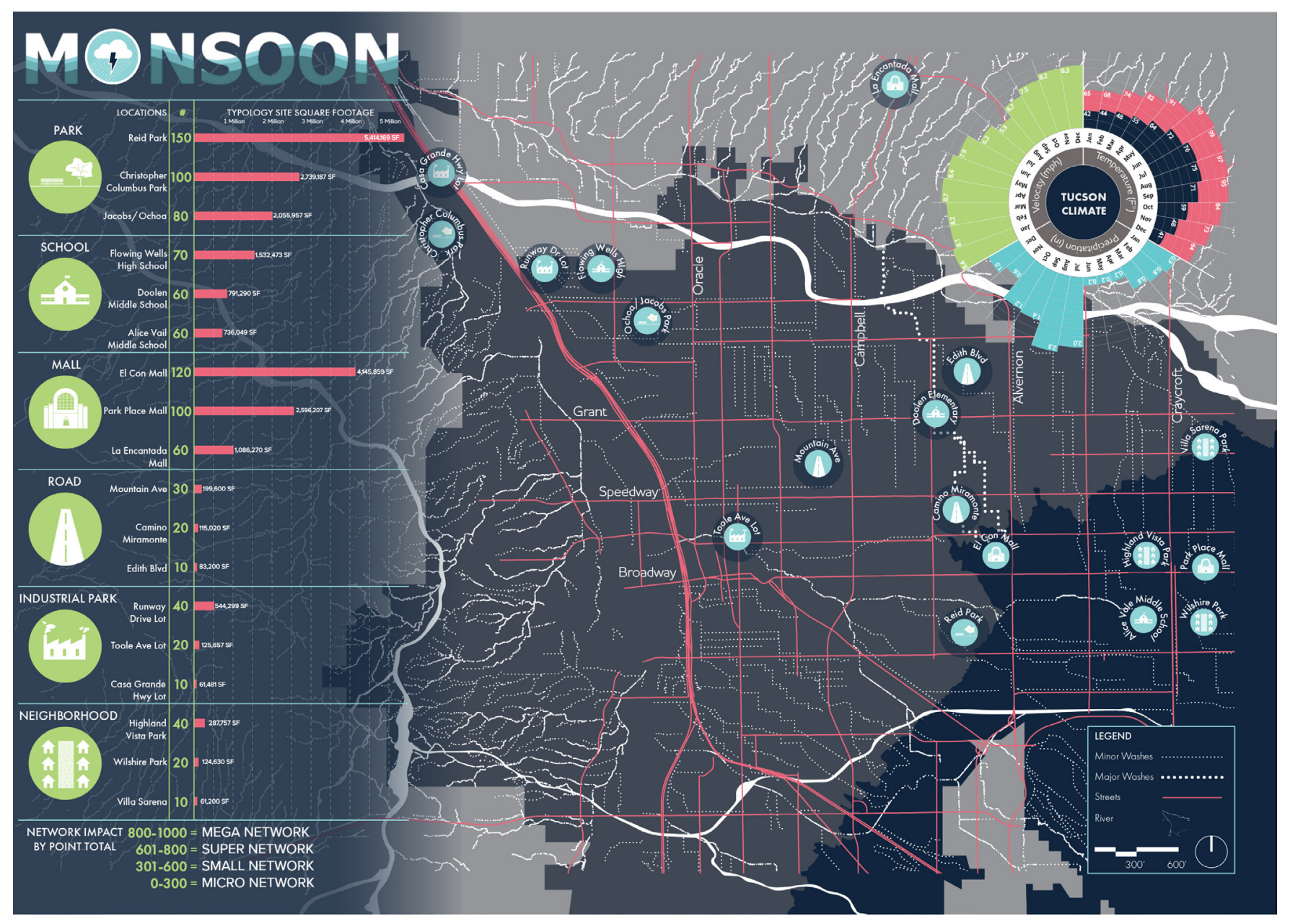

Figure 2. A map of the potential decentralized network of flood mitigation sites throughout Tucson studied by the Pima Water Urbanism Project in Fall 2018. (Credit: Amal Anoohi, Orianna Cascarano, Jeremy Goodman, Nan Liang, Rachel Low, Chung Lin, Peraya Mongkolwong, Madison Neperud, Irina Olson, Soha Sabet, Jason Sciarrotta, and Thomas Yazzie)

extreme precipitation if innovations are not made. However, municipalities also face resource constraints. Under limited budgets governments increasingly are asked to monitor, prevent, and respond to the impacts of climate change. Is there another answer to urban flooding than massive, top-down, and single-purpose public works? Can municipalities instead address urban challenges with a new paradigm: decentralized, bottom-up, and multi-benefit infrastructure?

This paper investigates this paradigm-shift in the growing Sonoran Desert city of Tucson, Arizona through the Pima Water Urbanism Project. The city faces two pressing and seemingly opposed challenges: (1) a projected shortage in local potable water supplies in the coming decades and (2) a seasonal excess of damaging floods from heavy monsoon rains. Tucson currently imports over a third of its water from the Colorado River 336 miles away, yet concurrently has the highest yearly extreme storm count across Western US Metropolitan Statistical Areas (MSAs). These urban water extremes affect citizens directly and disproportionately.
Tucson averages $\$ 9.5$ million in property losses each year from flooding in the city center where stormwater infrastructure was historically not installed, predominately in lower income areas.

Architects are called to play a greater leadership role in community design solutions for our future urban water challenges. Urban flooding and water resource management have traditionally been the domain of large public works projects led by civil engineers and public administrators. In contrast, new bottom-up infrastructural solutions are emerging in Tucson from neighborhood associations wishing to claim agency over annual, direct impacts. In a shift to support this civic action, the City is funding decentralized urban solutions at site, rather than dependence on large, centralized interventions. The City of Tucson recently approved competitive grants for Green Infrastructure (GI) implementation in neighborhoods throughout the City. This new network of small public works relies on citizen-architects as key agents of change. 

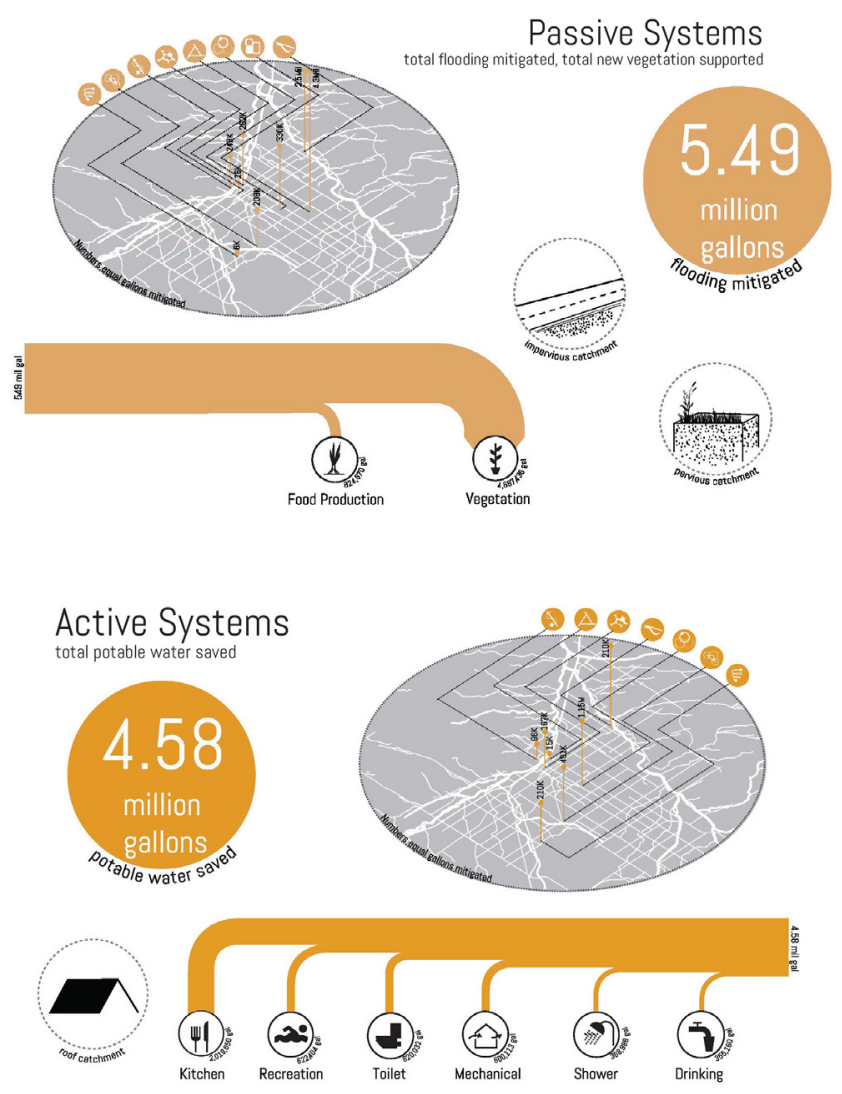

Figure 3. The aggregate impact of the passive and active systems across eight sites designed by the Pima Water Urbanism Project in Fall 2017. (Credit: Dana Ashoori, Christopher Bernhardt, Raul Castro Tohalino, Max Goldberg, Luis Griego, Daniel Jerrim, Delia Martinez, Matthew McCulloch, Robert Moreno, Morgan Nestegard, Truc Nguyen, Luz Rosario Pina, Brady Stanton, Kate Stuteville, Jazmine Tamayo, Jamil Williams)

This paper first reviews the challenges of retrofitting urban infrastructure for a changing climate. Then, through the Tucson case study, this paper seeks to debunk the myth that infrastructural projects are massive, top-down, and expensive. The paper provides three counter visions to retrofitting cities in the coming decades: decentralized networks, bottom-up processes, and multi-benefit design. Three example solutions from the Pima Water Urbanism Project are used to explore and deepen these visions: (1) Runway Drive, (2) Camino Miramonte, and (3) El Con Mall. The paper concludes that the case study is a replicable model for citizen-architects to join with governments and communities to together shift the urban infrastructure paradigm and provide solutions to some of the most pressing urban challenges.

\section{RETROFITTING CITIES FOR A CHANGING CLIMATE: THE CHALLENGE OF ADAPTABLE INFRASTRUCTURE IN THE COMING DECADES}

The critical challenge for contemporary urbanism is how cities develop the knowledge and capability to systematically re-engineer their built environment and urban infrastructure in response to climate change and resource constraints. ${ }^{5}$

What does our urban water infrastructure future hold? Climate change and deteriorating, aged infrastructure portend an urban water crisis in the coming decades. Over the next 25 years, the American Water Works Association (AWWA) and the American Society of Civil Engineers (ASCE), estimate a required investment of $\$ 1$ trillion for drinking water and $\$ 271$ billion for wastewater infrastructure to meet current and future water demands. This new, required investment could be put toward system innovations, however obstacles exist. Cities face a pattern of lock-in - seemingly "constrained by existing infrastructural investments, sunk cost, institutional rigidities, and vest interests." Additionally, inhibitory regulation, incentivized against risk, blocks the investment in innovative water solutions.

Tucson has a unique stormwater management history. The majority of the urban center of Tucson does not currently have storm water piping. Streets were designed to carry the heavy rain flows that occur during the winter and monsoon seasons to washes throughout the city. Over time, the city grew and greatly shifted its majority pervious land cover to impervious. This currently results in annual flooding in parts of the city leading to chronic property damage and loss in transportation accessibility. To address these issues, the County and City are working to collaboratively develop and optimize a network of sites that will address current flooding issues and retrofit Tucson with a new, softer, greener infrastructure.

\section{METHOD: WORKING BETWEEN GOVERNMENT EXPERTS AND PUBLIC ADOPTERS}

It is the designer's role to communicate to a broader public and to decision-makers the possibilities of implementing, or integrating new solutions... It is also the designer's role to engage the public in imagining new societies, new communities, and new ways of defining water, both culturally and physically. ${ }^{10,11}$

The Pima Water Urbanism Project provides community design solutions to urban flooding through collaboration with three community populations: (1) City and County staffs (including hydrologists, planners, and transportation engineers), (2) neighborhood residents and workers adjacent to sites of chronic flooding, and (3) emerging architects. Led through University of Arizona upper-level design studios from 2017-19, the project engages ten to sixteen Bachelors of Architecture students each year.

Pima County Regional Flood Control District (RFCD) has financially sponsored the Pima Water Urbanism Project over the last two years. Hydrologist form RFCD meet with students every other week during the course of the semester to provide supportive insight on the hydrology and flood mitigation strategies for their 


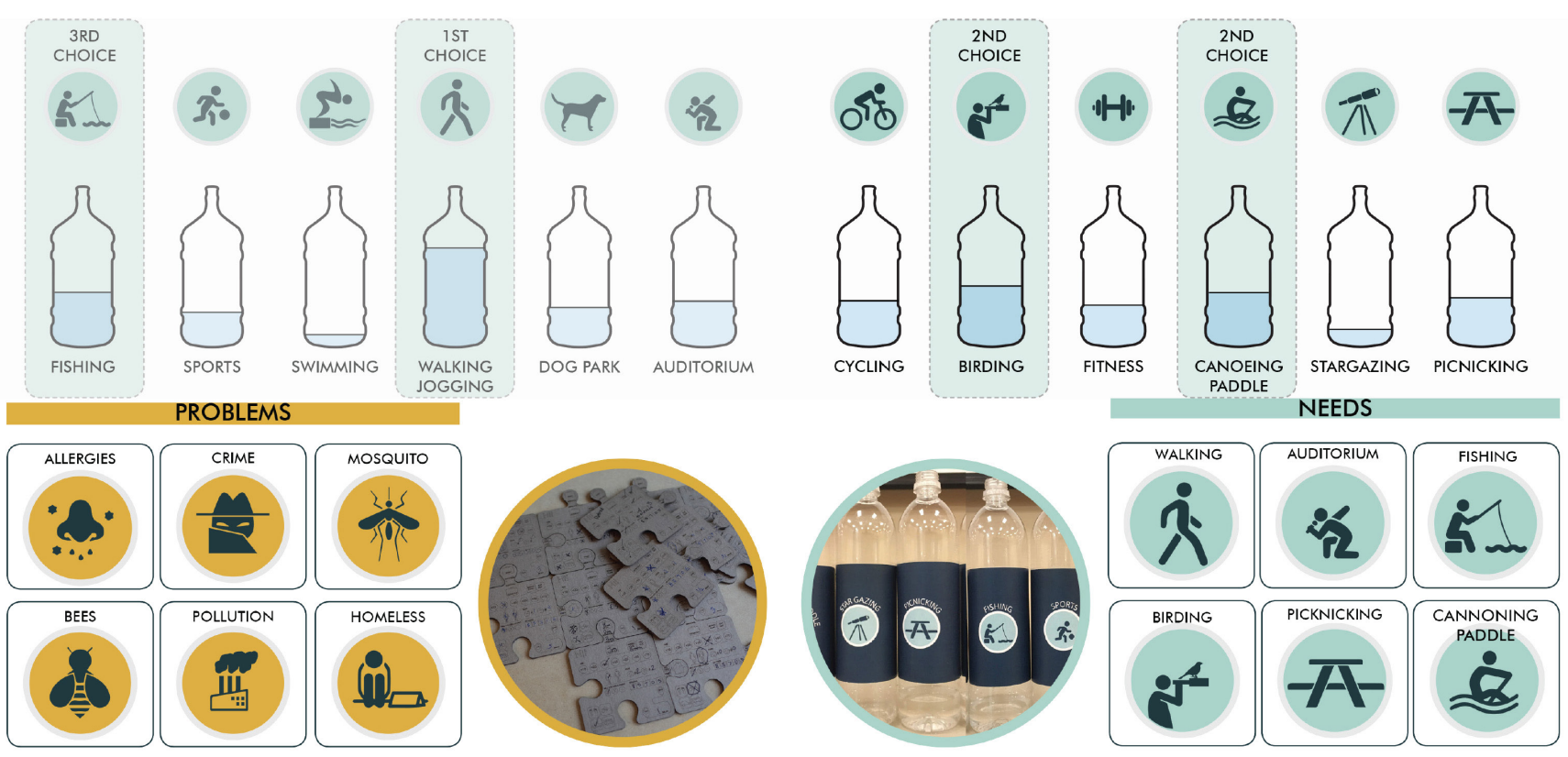

Figure 4. Community 'puzzle piece' surveys and voting for desired recreation options for the Runway Drive project. (Credit: Orianna Cascarano and Chung Lin)

sites. Site specific City of Tucson experts (e.g. transportation engineers, landscape architects, parks and recreation managers) also visit the class and provide critical feedback. Additionally, RFCD completes a set of three calculations during the course of the semester in tandem with design iteration. Students receive the total storage capacity for their site design and the percent of peak flow mitigated by their design. Through this analytical feedback from RFCD and City input, students continuously hone their designs to optimize flood mitigation and multiple desired community benefits. Figure 1 shows an active design session with a principal hydrologist from RFCD and, tudent designers of the Runway Drive project.

To date, the project has produced fourteen discrete community designs to alleviate specific sites of flooding throughout the city while expanding Tucson's overall infrastructure resilience. These solutions all employed community engagement in addition to the RFCD input. Solutions were collaboratively developed through local Ward meetings of affected communities and presentations to governmental decisionmakers including Pima County's Deputy Administrator, Tucson Parks and Recreation's Director, Tucson Water's Conservation Manager, and Tucson Department of Transportation's Director. Each of these projects engaged with the direct communities that used the sites to identify community needs - whether adjacent autobody shop workers who desired a place to eat their lunch or the neighborhood association who advocated for a dog park. The work has been broadly disseminated through open-access electronic and printed material outlets, presentations and engagement activities at local Ward meetings, and the creation of a card game called 'Monsoon.'

\section{THE MYTH OF MASSIVE INFRASTRUCTURE: GROWING DECENTRALIZED NETWORKS}

The first infrastructure myth this paper seeks to debunk through the Tucson case is that interventions must be massive to have an impact. Urban water systems have traditionally been built as large, extensive public works. Grand aqueducts have been constructed across states, mighty dams have been built surmounting height and hydrostatic force, and stormwater treatment plants have been developed on the edges of cities. These massive infrastructure projects have ensured centralized control of water quality and quantity. However, under mounting deferred maintenance, failing water infrastructure around the county portends a coming water crisis. Rather than replace these systems, an incremental approach may be the best answer. David Sedlak, civil engineer and author of Water 4.0, asserts that "to wean cities from centralized systems and all their associated problems, we might simply have to find a way to make decentralized water supply and treatment practical at higher population densities." Decentralized systems can add resilience to existing infrastructure through providing multiple pathways to collect and deliver resources within a municipality. By hybridizing the existing city water system with decentralized solutions, these new interventions can strengthen infrastructure by providing flexibility to respond to uncertain shocks.

The Pima Water Urbanism Project approaches Tucson's flooding challenges as urban acupuncture. Through a network of decentralized interventions that directly address the areas of chronic flooding, localized and aggregate impacts are achieved. Figure 2 shows the decentralized 

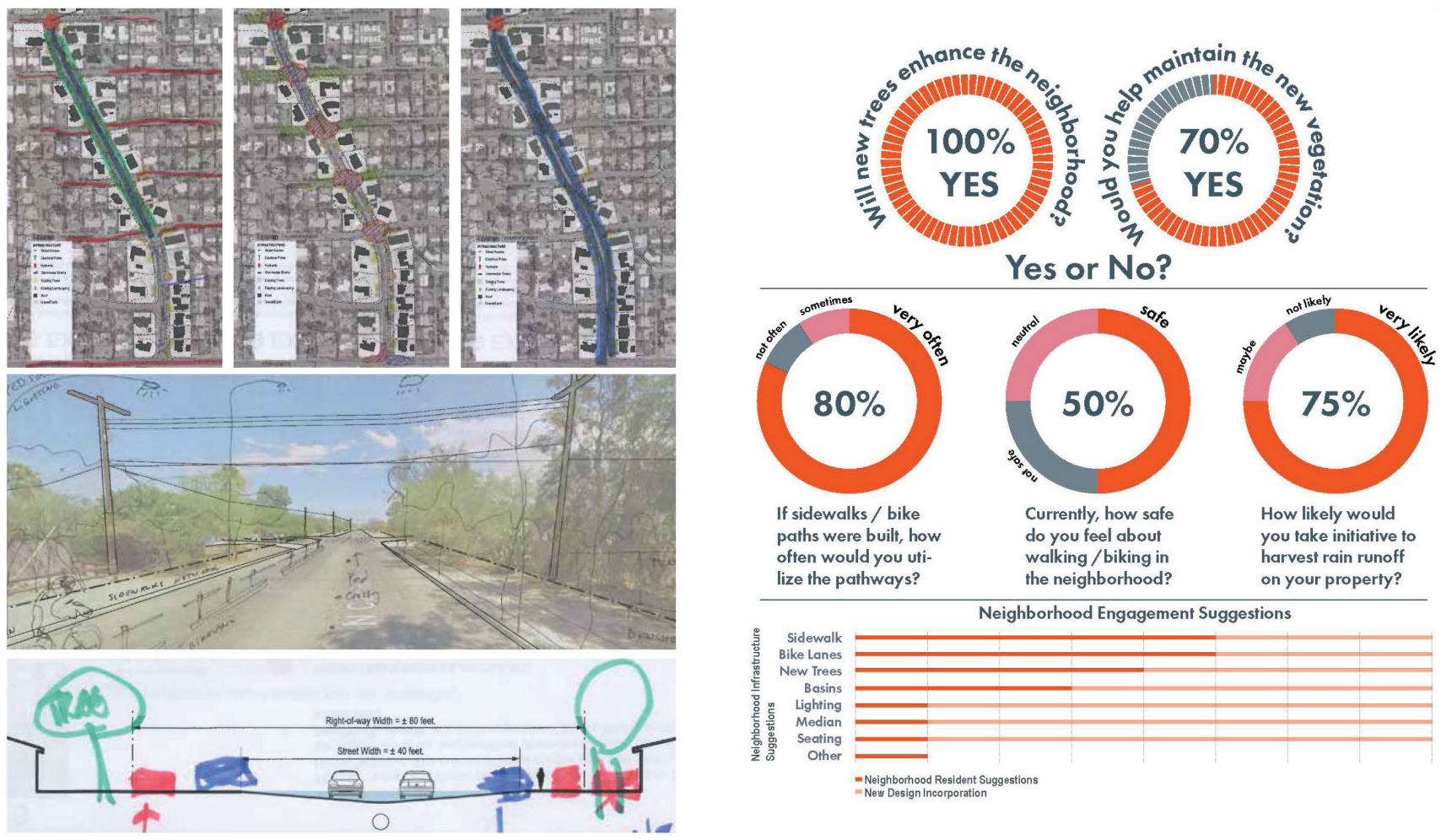

Figure 5. Results from the Camino Miramonte Neighborhood Association survey. (Credit: Amal Anoohi and Thomas Yazzie)

network of projects throughout Tucson by students during the Fall 2018. Interventions are broken into a set of typologies: park, school, mall, road, industrial park, and neighborhood. Each typology was codified through the identification of similar constituencies and approaches to flood mitigation. For example, the Runway Drive project belongs to the industrial park typology. This typology has larger sized sites, workers as constituents (rather the residents), and employs strategies of deep basins to handle the usually large flooding volumes in the industrially zoned areas. The Camino Miramonte project is in the road typology. This typology is comprised of the inverted crown streets in Tucson that channel stormwater to washes, but have exceeded their designed capacity due to surrounding increases in impervious surfaces. Strategies in this typology rely on linear elements in the right-of-way and smaller interventions like roundabouts that can address inverted crown flooding. Pedestrian safety and expanded and protected bicycle lanes are common benefits. The El Con Mall project belongs to the mall typology. Malls have large impervious parking lot surfaces that can be retrofitted with microbasins throughout the lot and multi-use basins in demolished areas of over-built parking. These solutions usually provide benefits to communities adjacent to the mall parking lot sites. Through creating typological solutions, similar applications can be added to the decentralized network throughout Tucson in an incremental approach.
Additionally, a kit-of-parts was constituted for each design. These kit-of-parts help future designers use the projects as examples and identify the requisite pieces to address a typology. Students were required to compute budgets for their designs. The itemized kit-of-parts helped the students complete the budget exercise and the County and City identify common modules to be manufactures and/or regulated and/ or provided with new design parameters for the future replicable network.

Overall, Figure 3 provides an example of how passive and active water harvesting in a decentralized network accomplish the city-wide goals in aggregate. In the figure, eight sites designed by the Pima Water Urbanism Project from Fall of 2017 form a decentralized network able to mitigate 5.49 million gallons of flooding per year, offset 4.58 million gallons of potable water use per year, and provide local co-benefits such as reduced heat island and expanded recreation opportunities.

\section{THE MYTH OF TOP-DOWN INFRASTRUCTURE: SUPPORTING BOTTOM-UP PROCESSES}

The second myth is that infrastructure projects must be topdown due to size and complexity. Globally, water projects are infamous for a top-down approach. The building of dams, reservoirs, and aqueducts have a history of displacing communities around the world. In contrast, the decentralized network approach increasingly calls on community members 

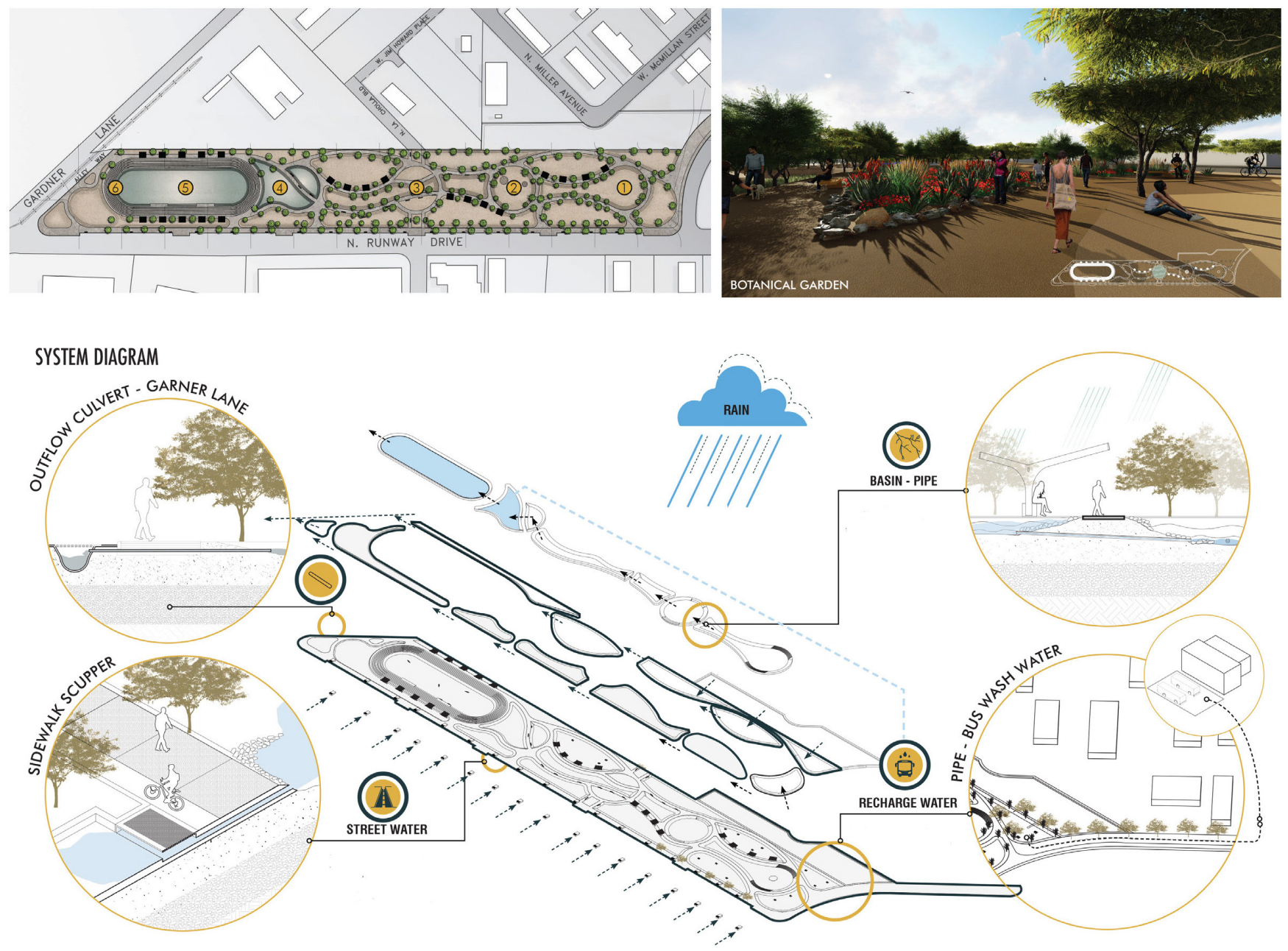

Figure 6. The Runway Drive project mitigated flooding and provided multi-benefits to the community like expanded recreation opportunities and places to eat lunch for adjacent workers. (Credit: Orianna Cascarano and Chung Lin)

to provide long-term monitoring of the sites. The municipality does not usually have the extra staff and resources to provide more oversight to scattered projects throughout a city. Thus, initial community buy-in is critical to the long-term success of this new infrastructure paradigm.

Before the start of the semester, RFCD provides a set of sites with hydrological maps and graphs to the professor. The projects are selected for the urgency of the flooding issue, the site's potential to have impact on the issue, and the County or City's ownership or ability to negotiate ownership of the site. Beyond mitigating flooding, the value of the student designers is to engage the unique stakeholders of each site and work with them to maximize the potential benefits of the site. The first step in each project's community engagement is to contact the Ward and representative city councilmember for the site. It is important to start with the Wards as the base gatekeepers between the neighborhoods and the city council. Tucson has six wards, each with a city councilmember. Students meet with the Ward staff and councilmember with representatives from
RFCD and professor to discuss initial design ideas. Students receive feedback, information on any locally relevant history of the sites, and a list of potential stakeholders.

Students are then asked to identify the community groups to engage, their questions for those groups, and design a process that successfully engages those groups in providing the needed feedback. In Figure 4, one of the engagement methods and results are shown for the Runway Drive project. Runway Drive is the runway of a former small airport surrounded by industrial businesses including air conditioning mechanics, the headquarters for the SunTran regional bus system, autobody painters, and waste controllers. These students wanted to understand the specific issues and perceived assets of the site by the surrounding business community. They created a survey on laser cut puzzle pieces for each worker to complete. Additionally, the students wanted to clarify the preferred future uses of the multi-use basins. They developed a voting scheme using water bottles where each community member voted with a tablespoon of water for their favorite 


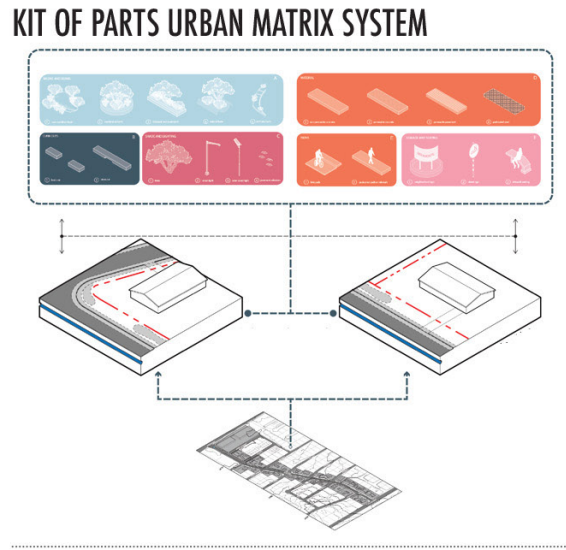

BLOCK MATRIX SYSTEM

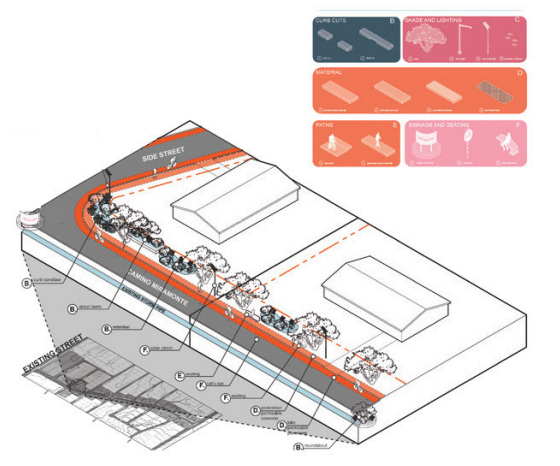

PASSIVE WATER SYSTEM

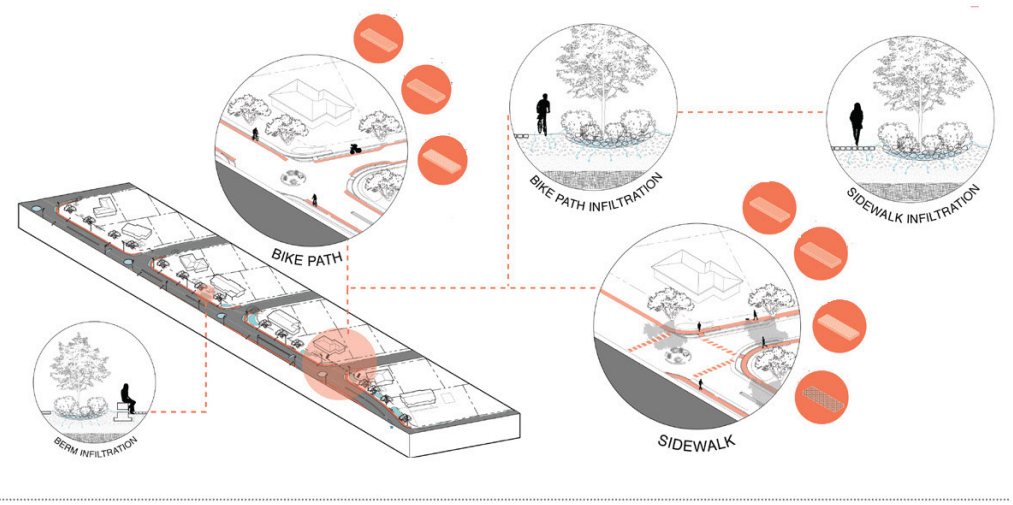

SIGNAGE AND INFRASTRUCTURE

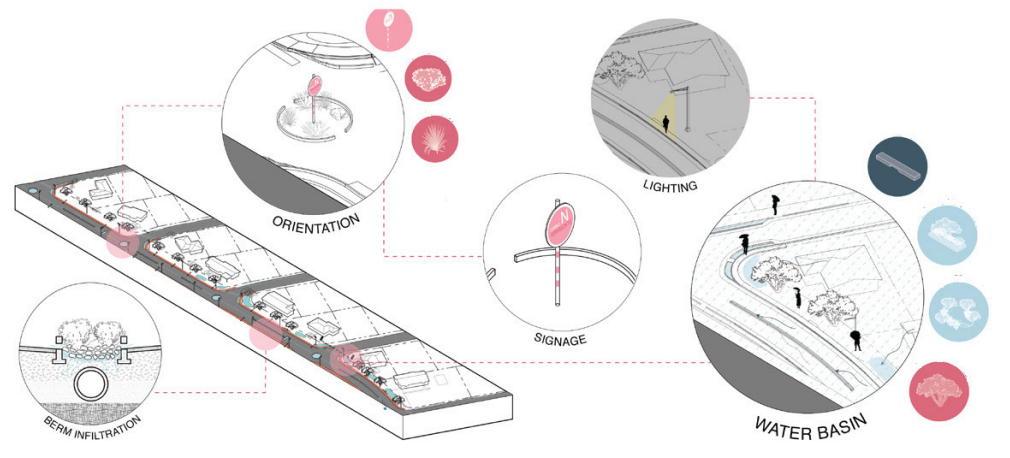

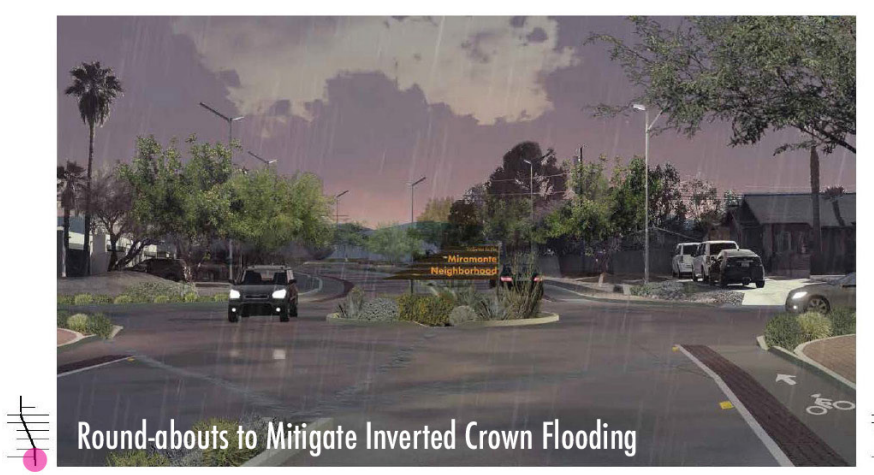

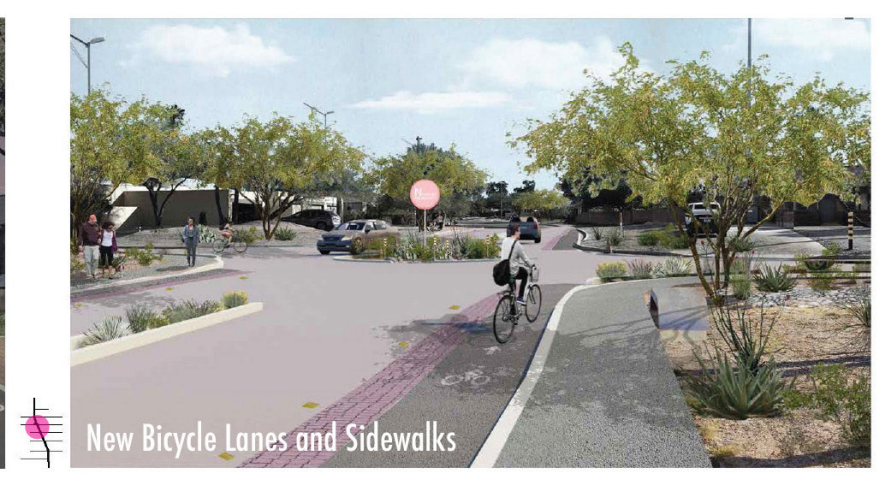

Figure 7. The Camino Miramonte project mitigated flooding and provided multi-benefits to the community like expanded bicycle paths and improved pedestrian safety. (Credit: Amal Anoohi and Thomas Yazzie)

activity. In addition to going door-to-door to the surrounding businesses, the students also participated in a community potluck for Thanksgiving at the Flowing Wells Neighborhood Association. Students gave a presentation of the site with initial design ideas and asked for feedback and water voting. Using all this information, the students designed the site to incorporate the preferred recreation options and mitigated the identified concerns.

The Camino Miramonte project engaged with the Camino Miramonte Neighborhood Association. The students asked the neighbors to fill out a visual survey (drawing desired changes) and text survey. Figure 5 shows the results of these surveys. Students confirmed the local enthusiasm for the conversion of the street and a general willingness to maintain the improvements. Complaints on the long-standing issue and aborted promises from the City were also heard by the students. These engagement exercises exposed young designers to the messiness of working with communities, particularly on projects that have a deep prior history to their work.

In the last example of El Con Mall, students designed a game for their annual neighborhood associating meeting and general canvassing at the El Con site. A large gator board was laser cut with holes where stakeholders could place color coded pieces representing different potential benefits of the project. 

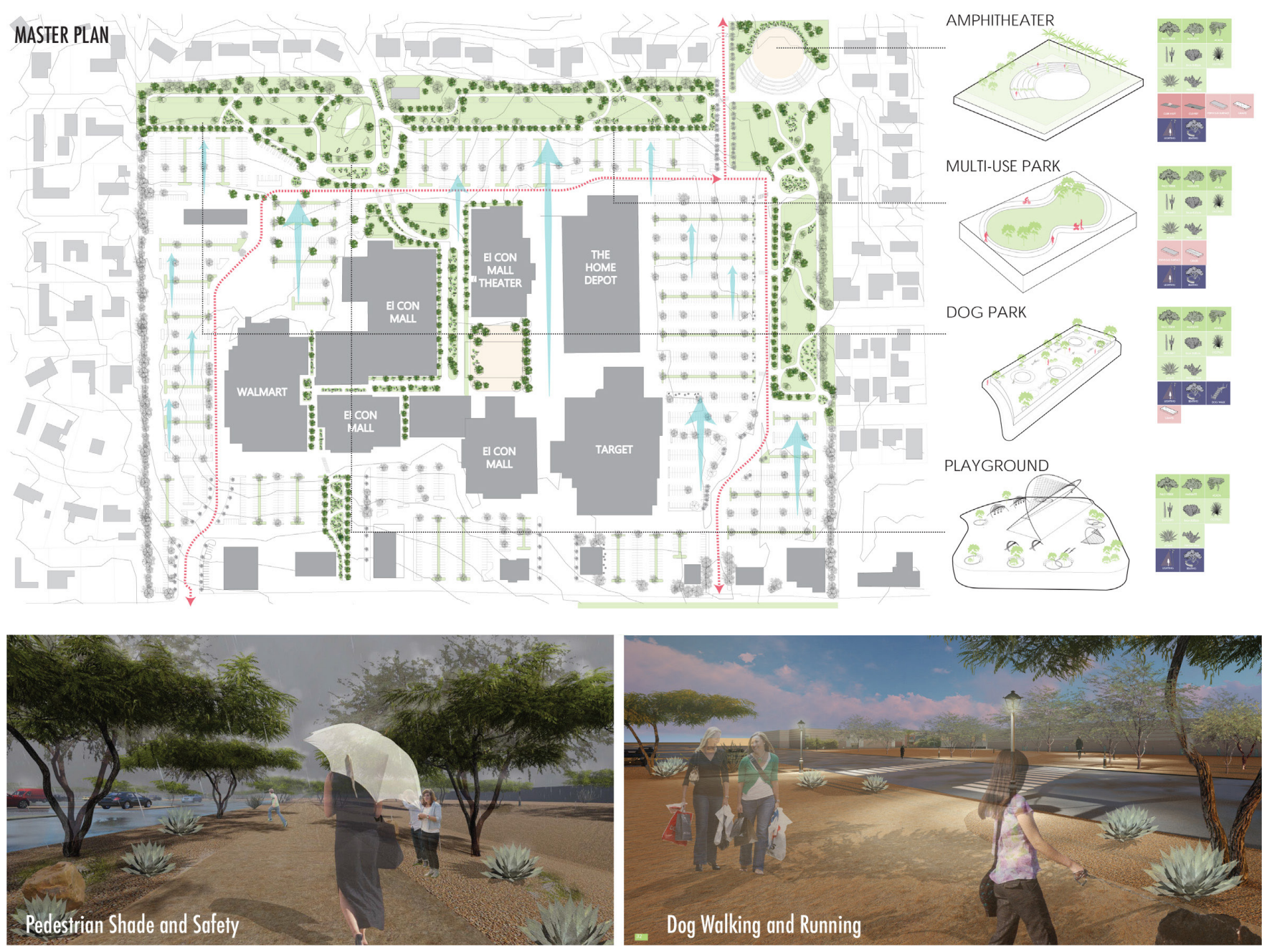

Figure 8: The El Con Mall project mitigated flooding and provided multi-benefits to the community like playgrounds, dog parks, running paths and heat island mitigation. (Credit: Peraya Mongkolwong and Irina Olson)

The community was also asked about the current 8-foot wall separating the neighborhood from the Wal-Mart parking lot. To the students' disappointment, a great majority of the community wanted to keep the wall, even if a green park buffer were to be constructed. This exchange taught students about the friction between community desires and what they perceive as the best design solution.

\section{THE MYTH OF EXPENSIVE INFRASTRUCTURE: EXPANDING MULTI-FUNCTION AND MULTI-BENEFIT SOLUTIONS}

The final myth is that all infrastructure projects are expensive. Urban infrastructure has traditionally been built as singlepurpose systems, each with a single value. Roads systems move traffic efficiently, energy lines transmit power, and stormwater culverts transport water quickly to the periphery of the city. In a new era of climate change and growing technological resources, urban infrastructures are increasing seen as amateurs for multiple functions. Roads now provide shaded paths for a healthier and more active population as well as opportunities for passive stormwater harvesting. These multiple purposes shift an assessment of infrastructure from a simple pay-back on a fixed investment to a complex life-cycle cost assessment of the social, ecological, and financial valuation of public works. In Out of Water: Design Solutions for Arid Regions, Liat Margolis and Aziza Chaouni highlight that this new approach is important to designers of cities: "The shift toward multi-objective optimization at the regional and metropolitan scales offers designers and planners the opportunity to rethink emergent infrastructural landscapes as a socio-cultural, economic, and ecological extension of the city." This conception also requires the breaking of departmental silos within municipalities for cross-sector collaboration to realize multi-benefit infrastructure projects.

The Pima Water Urbanism Project uses each intervention to mitigate flooding, but also to provide a host of layered community benefits. The unique water extremes of Tucson provide 
a particularly good opportunity to design basins to mitigate peak events that occur over a few dozen days per year while layering community uses for the other days of the year in the sunny climate. In this way, infrastructure investments are no long seen as huge expenses, but rather long-term community investments to provide multiple solutions for public betterment. As the networked decentralized system is able to mitigate specific sites of flooding, it is also able to provide tailored community multi-benefits.

The Runway Drive project (Figure 6) converts a former airport landing strip to a set of large basins to provide the local community with increased green space and recreation opportunities. This area of the city has a deficit of urban green space. Also, the project uses a large weekly supply of filtered bus washing water from the adjacent SunTran regional bus center to maintain water levels in a community-desired fishing pond. Other basins address community needs like running paths, playgrounds, and birding. The area is a new lunch spot for all the industrial area workers to get a break from their work and a new haven for urban wildlife.

The Camino Miramonte project (Figure 7) takes a wide inverted crown street and converts it to a set of water retention devises like corner basins, side basins, and roundabout basins. Shading and street furniture and larger gathering spaces for the neighborhood are added. A bicycle lane flanks each side of the street. Overall, pedestrian and bicycle safety are expanded.

El Con Mall is termed the current headwaters of chronic downstream neighborhood flooding. The El Con Mall project (Figure 8) transforms an underutilized expanse of parking lots to basins and community parks. A dog park, playground, and amphitheater are added amenities. Linear microbasins are integrated throughout the retained parking lots, providing shade and decreasing heat island impact. A running track that also serves as a green-belt around the site to absorb water is implemented. Finally, the adjoining neighborhood to the north is given a continuous walking path to connect their homes to the large municipal park on the southern side of the mall. Overall, the residents receive a larger and softer buffer with the imposing commercial center, recreation opportunities, and modest reductions in heat island effects.

\section{CONCLUSION: A REPLICABLE MODEL CREATING NEW PROJECT OPPORTUNITIES FOR PRACTICE}

Rather than standing in for architectural practice, the Pima Water Urbanism Project aims to open new doors for future partnerships between professional architects and the City and County. In one recent example, the owner of El Con Mall agreed to sell several parking lot areas to the City based on the produced vision from the project. The City will now go forward with a new Request for Proposal open to professional practice. In another recent success, Tucson Department of Transportation (TDOT) approved the technical drawings to fund and build the components of the Camino
Miramonte project. The councilmember and neighborhood association has used the design and renderings to successfully advocate to the City to build the infrastructure project.

The Pima Water Urbanism Project is a replicable model for architectural academia to join with local communities and government staffs to provide practical solutions to urban water challenges through a network approach. The community design project proves that the model can (1) coordinate and leverage the necessary local resources and expertise to impact pressing urban design issues through decentralized systems thinking, (2) teach future architects to be key agents in bottom-up solutions to urban-scale challenges through onsite design solutions, and (3) engage with stakeholders specific to each flooding site to support needed co-benefits for that community. Because of the successful phase one work, this partnership model has secured funding from Pima County Regional Flood Control District to continue to develop solutions with affected communities throughout Tucson.

To view the full set of community design projects developed as a part of this program, please use these links:

- https://issuu.com/universityofarizonaschoolofarchitec/ docs/runway_drive_-_studio_crosson

- https://issuu.com/universityofarizonaschoolofarchitec/ docs/camino_miramonte___studio_crosson

- https://issuu.com/universityofarizonaschoolofarchitec/ docs/el_con_mall_-_studio_crosson

\section{ENDNOTES}

1. Wuebbles, Donald J., David W. Fahey, and Kathy A. Hibbard. "Climate science special report: fourth national climate assessment, volume I." (2017).

2. Ibid.

3. Bakkensen, Laura and Riana Johnson. "The Economic Impacts of Extreme Weather: Tucson and Southern Arizona's Current Risks and Future Opportunities." Making Action Possible for Southern Arizona, 2017.

4. Ibid.

5. Hodson, Mike, and Simon Marvin, eds. After Sustainable Cities? Routledge, 2014.

6. American Water Works Association. "State of the Water Industry." Washington DC: AWWA, March 2016.

7. American Society of Civil Engineers. "2017 Infrastructure Report Card." ASCE, 2017. (Accessed 25 July 2017). www.infrastructurereportcard.org.

8. Graham, Stephen, and Nigel Thrift. "Out of Order: Understanding Repair and Maintenance." Theory, Culture \& Society 24, no. 3 (2007): 1-25.

9. Crosson, Courtney. "Innovating the Urban Water System: Achieving a Net Zero Water Future Beyond Current Regulation." Technology/ Architecture+ Design 2, no. 1 (2018): 68-81.

10. Margolis, Liat, and Aziza Chaouni. Out of Water-Design Solutions for Arid Regions. Birkhäuser, 2014.

11. Nassauer, Joan Iverson. "Landscape as Method and Medium for the Ecological Design of Cities." In Resilience in Ecology and Urban Design, pp. 79-98. Springer, Dordrecht, 2013.

12. Sedlak, David. Water 4.0: The Past, Present, and Future of the World's Most Vital Resource. New Haven: Yale University Press, 2014

13. Margolis, Liat, and Aziza Chaouni. Out of Water-Design Solutions for Arid Regions. Birkhäuser, 2014. 